Enders, W., So Im, K., Lee, J., and Strazicich, M.C. (2010). IV Threshold Cointegration Tests and the Taylor Rule. Economic Modelling, 27(6): 1463-1472 (Nov 2010). Published by Elsevier (ISSN: 0264-9993).

doi:10.1016/j.econmod.2010.07.013

\title{
IV threshold cointegration tests and the Taylor rule
}

Walter Enders, Kyung So Im, Junsoo Lee, and Mark C. Strazicich

\begin{abstract}
The usual cointegration tests often entail nuisance parameters that hinder precise inference. This problem is even more pronounced in a nonlinear threshold framework when stationary covariates are included. In this paper, we propose new threshold cointegration tests based on instrumental variables estimation. The newly suggested IV threshold cointegration tests have standard distributions that do not depend on any stationary covariates. These desirable properties allow us to formally test for threshold cointegration in a nonlinear Taylor rule. We perform this analysis using real-time U.S. data for several sample periods from 1970 to 2005. In contrast to the linear model, we find strong evidence of cointegration in a nonlinear Taylor rule with threshold effects. Overall, we find that the Federal Reserve is far more policy active when inflation is high than when inflation is low. In addition, we reaffirm the notion that the response to counteract high inflation was weakest in the 1970s and strongest in the Greenspan era.
\end{abstract}




\section{INTRODUCTION}

A large and growing literature utilizes a threshold regression (TR) to capture the nonlinear relationships found among many macroeconomic variables. As in the linear regression framework, the estimation results from nonlinear regressions will be spurious if nonstationary I(1) variables are not cointegrated. In this regard, Balke and Fomby (1997) examined threshold cointegration by assuming that cointegration exists within a certain range of deviations from the long-run equilibrium implied by the null, but did not provide formal tests for threshold cointegration. Enders and Siklos (2001) provide critical values for threshold cointegration tests in a specific threshold specification that permits asymmetric adjustment in the error correction term. Nevertheless, testing for threshold cointegration is difficult when the distributions of the relevant test statistics depend on nuisance parameters. For example, the usual cointegration tests will depend on a nuisance parameter when stationary covariates are included, and the problem becomes even more pronounced in a nonlinear framework. However, bootstrapping the critical values does not appear a good solution in such cases. Enders et al. (2007) find that bootstrapping a test for persistence in a TR leads to excessively wide confidence intervals.

In this paper, we adopt a new methodology using instrumental variables (IV) estimation where, with one caveat, inference in a TR can be undertaken free of nuisance parameters. For this purpose, we extend the linear IV cointegration tests of Enders et al. (2009) and introduce new IV threshold cointegration tests can result in test statistics that can have standard normal, $t, F$ or $x^{2}$ distributions. This outcome permits us to perform inference without the necessity of bootstrapping or using nonstandard distributions that depend on the particular model specification. In our methodology, the asymptotic distributions of threshold cointegration, weakexogeneity, and symmetry tests are all standard even when stationary covariates are included. Monte Carlo experiments demonstrate that the IV threshold cointegration test has reasonable size and power properties.

Then, we apply our methodology to test for threshold cointegration in a nonlinear Taylor rule (Taylor, 1993). There are strong reasons to believe that modeling the Taylor rule is especially amenable to our methodology. Given a growing body of literature on testing nonlinear Taylor rules, it is somewhat surprising that no paper performs tests for nonlinear cointegration. However, this outcome may be due to difficulties found in the existing tests. To explain the issues involved, consider a standard linear Taylor rule specification:

$$
\begin{aligned}
i_{t} & =r^{*}+\pi_{t}+\alpha_{1}^{*}\left(\pi_{t}-\pi^{*}\right)+\alpha_{2} y_{t}+\alpha_{3} i_{t-1}+\alpha_{4} i_{t-2}+\varepsilon_{t} \\
& =\alpha_{0}+\alpha_{1} \pi_{t}+\alpha_{2} y_{t}+\alpha_{3} i_{t-1}+\alpha_{4} i_{t-2}+\varepsilon_{t},
\end{aligned}
$$

where $i_{t}$ is the nominal federal funds interest rate, $r^{\mathbb{P}}$ is the equilibrium real interest rate, $\pi_{t}$ is the average inflation rate over the previous four quarters, $\pi^{\mathbb{R}}$ is the central bank's inflation target, $y_{t}$ is the "output gap" measured as the percentage deviation of real GDP from potential real GDP, $\alpha_{0}=r^{\boxplus}-\alpha_{1}^{\square} \pi^{\boxplus}, \alpha_{1}=1+\alpha_{1}^{\square}$, and $\varepsilon_{t}$ is an error term. The lagged terms $i_{t-1}$ and $i_{t-2}$ are included to allow for the possibility of interest rate smoothing, where adjustment to the target rate is gradual. 
The recent macroeconometric literature suggests that simple OLS or GMM estimation of Eq. (1) may not be appropriate. For example, Bunzel and Enders, 2010 and Österholm, 2005 show that the federal funds rate and inflation rate act as unit root processes and the output gap is stationary. These papers employ a battery of Johansen, 1988 and Johansen, 1991 cointegration tests and conclude that there is no meaningful linear cointegrating relationship between the inflation rate, output gap, and federal funds rate. We reconfirm similar results in this paper using real-time data. Concurrently, a growing body of literature suggests that the relationship between the federal funds rate, output gap, and inflation rate is likely to be some form of nonlinear regime-switching model; see, for example, the papers by Bec et al., 2002, Boivin, 2006, Taylor and Davradakis, 2006 and Qin and Enders, 2008. Intuitively, we note that the model specification in Eq. (1) already shows possible instability in its underlying parameters. For

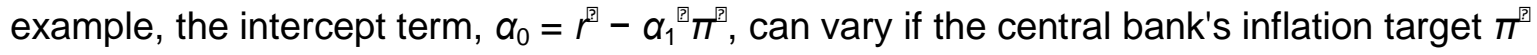
changes. Furthermore, to the extent that the Federal Reserve is more concerned about high inflation than low inflation, the response of $i_{t}$ is expected to be more dramatic when inflation is above the target rate than when inflation is below the target. Moreover, if it is more difficult for the Fed to reduce inflation than to increase inflation, the response of $i_{t}$ should be greater for positive values of $\left(\pi_{t}-\pi^{\text {? }}\right)$ than for negative values. Since similar arguments can be made regarding the relationship between $i_{t}$ and the output gap, it seems reasonable to modify Eq. (1) to estimate the relationship between $i_{t}, \pi_{t}$ and $y_{t}$ in a threshold framework. However, this poses an important fundamental question. In order to correctly estimate a Taylor rule with threshold effects, we must first know if a threshold cointegrating relationship exists.

Testing for threshold cointegration in a nonlinear Taylor rule is complicated by (a) the presence of the stationary covariate $y_{t}$, (b) the presence of the lagged interest rate terms, and (c) the possibility that the variables in the model are jointly endogenous. While a researcher might want to include $y_{t}, i_{t-1}$ and $i_{t-2}$ in a test for cointegration between $i_{t}$ and $\pi_{t}$ in order to reduce the estimated variance of the error term, including these variables will cause the test statistics to depend on nuisance parameters. Perhaps for these reasons, the literature has been silent in providing evidence of threshold cointegration in a nonlinear Taylor rule. Indeed, the extant literature does not contain a straightforward threshold cointegration test without nuisance parameters. As we will demonstrate, by including stationary IV in our tests we can conduct statistical inference concerning cointegration and threshold behavior in a nonlinear Taylor rule without the need to resort to a bootstrap procedure.

To preview our empirical findings, we show that the behavior of the Federal Reserve during the Burns-Miller period was very different from that during the Volcker and Greenspan periods. For each subsample beginning with the Paul Volcker era, our testing procedure indicates the presence of a significant threshold cointegrating relationship in a nonlinear Taylor rule. A particularly interesting result is that the Federal Reserve is far more policy active when inflation is high than when inflation is low. While these findings are robust to several different time periods, we find that the Federal Reserve was most aggressive to counteract inflation during the Greenspan era and least aggressive in the 1970s.

The paper proceeds as follows. In Section 2, we describe our testing methodology. The asymptotic properties are derived and finite sample properties are examined in simulations. 
Proofs are provided in Appendix A. In Section 3, we present our empirical findings of testing for threshold cointegration in a nonlinear Taylor rule. Concluding remarks are provided in Section 4.

\section{ESTIMATION AND TESTING METHODOLOGY}

In this section, we present a general testing methodology for threshold cointegration that, with one caveat, avoids the nuisance parameter problem. Consider the following threshold autoregressive distributed lag (ADL) model:

$\Delta x 1 t=\left[\alpha_{11} x 1, t-1+\alpha_{12}^{\prime} x 2, t-1+\phi_{11}^{\prime} d t+\phi_{12}^{\prime} s t\right] / 1 t+\left[\beta_{11} x 1, t-1+\beta_{12}^{\prime} x 2, t-1+\gamma^{\prime}{ }_{11} d t+\gamma_{12}^{\prime} s f\right] / 2 t+u 1 t \Delta x 1 \mathrm{t}=[\alpha 11$ $\left.\mathrm{x} 1, \mathrm{t}-1+\alpha^{\prime} 12 \mathrm{x} 2, \mathrm{t}-1+\phi^{\prime} 11 \mathrm{dt}+\phi^{\prime} 12 \mathrm{st}\right] \mid 1 \mathrm{t}+\left[\beta 11 \mathrm{x} 1, \mathrm{t}-1+\beta^{\prime} 12 \mathrm{x} 2, \mathrm{t}-1+\gamma^{\prime} 11 \mathrm{dt}+\gamma^{\prime} 12 \mathrm{st}\right] 12 \mathrm{t}+\mathrm{u} 1 \mathrm{t}$

$\Delta x 2 t=\left[\alpha_{21} x 1, t-1+\alpha_{22}^{\prime} x 2, t-1+\phi_{21}^{\prime} d t+\phi_{22}^{\prime} s t\right] / 1 t+\left[\beta_{21} x 1, t-1+\beta_{22}^{\prime} x 2, t-1+\gamma_{21}^{\prime} d t+\gamma_{22}^{\prime} s t\right] / 2 t+u 2 t \Delta x 2 \mathrm{t}=[\alpha 21$ $\left.\mathrm{x} 1, \mathrm{t}-1+\alpha^{\prime} 22 \mathrm{x} 2, \mathrm{t}-1+\phi^{\prime} 21 \mathrm{dt}+\phi^{\prime} 22 \mathrm{st}\right] \mid 1 \mathrm{t}+\left[\beta 21 \mathrm{x} 1, \mathrm{t}-1+\beta^{\prime} 22 \mathrm{x} 2, \mathrm{t}-1+\gamma^{\prime} 21 \mathrm{dt}+\gamma^{\prime} 22 \mathrm{st}\right] 12 \mathrm{t}+\mathrm{u} 2 \mathrm{t}$

$I_{1 t}=I\left(h_{t}>\tau\right)$ and $I_{2 t}=1-I_{1 t}, 11 \mathrm{t}=\mathrm{I}(\mathrm{ht}>\mathrm{T})$ and $2 \mathrm{t}=1-\mathrm{I} 1 \mathrm{t}$,

where $x_{t}=\left(x_{1 t}, \ldots, x_{p t}\right)^{\prime}$ is a $p$-dimensional $/(1)$ time series, $d_{t}$ includes a constant term (or all relevant deterministic terms) and lagged differenced terms that correct for serial correlation, $s_{t}$ includes one or more stationary right hand variables, and $u_{t} \sim N(0, \Sigma) . l_{1 t}$ is a Heaviside indicator such that $l_{1 t}=1$ if $h_{t}>t$ and $l_{1 t}=0$ otherwise, where $h_{t}$ is the threshold variable (or function) and $\tau$ is the threshold value or parameter. If desired, we can allow for a delay parameter $d$, where $h_{t}$ is replaced throughout with $h_{t-d}$. Following Li and Lee (2010), we adopt percentiles of the threshold variable and consider different indicator functions where the threshold variable $h_{t}$ can be $I(0)$ as in Hansen and Seo (2002) or $I(1)$ as in Seo (2006). When $h_{t}$ is $I(0)$,

$I 1 t=I(h t>T)=I\left(h t>h t^{*}(c)\right) \rightarrow I(U(r)>C), I 1 \mathrm{t}=\mathrm{I}(\mathrm{ht}>\mathrm{T})=\mathrm{Iht}>\mathrm{ht}{ }^{*} \mathrm{C} \rightarrow \mathrm{IUr}>\mathrm{C}$,

where $h_{t}^{\square}(c)$ denotes the threshold value which is the $c$-th percentile of the empirical distribution of $h_{t}$ and $U(r)$ is a univariate process having a uniform distribution on $r \in[0,1]$. Alternatively, when $h_{t}$ is $l(1)$,

$I 1 t=I(h t>T)=I\left(\sigma-1 T-1 / 2 h t>\sigma-1 T-1 / 2 h t^{*}(c)\right) \rightarrow I\left(W(r)>W^{*}(c)\right), I 1 \mathrm{t}=\mathrm{I}(\mathrm{ht}>\mathrm{T})=\mathrm{l} \sigma-1 \mathrm{~T}-1 / 2 \mathrm{ht}>\sigma-1 \mathrm{~T}-1 / 2 \mathrm{ht} \mathrm{t}^{*}$ $\mathrm{c} \rightarrow \mathrm{I}\left(\mathrm{Wr}>\mathrm{W}^{*}(\mathrm{c})\right)$,

where $W(r)$ is a Brownian motion on $r \in[0,1], \sigma^{2}=T^{1} E(\Sigma \Delta h t)^{2} \Sigma \Delta h t 2, h_{t}^{\square}(c)$ denotes the threshold value which is the $c$-th percentile of the empirical distribution of the normalized $h_{t}$, and 
$W^{*}(c)$ is a Brownian motion using a sorted time series evaluated at the $c$-th percentile. Thus, in both indicator functions, the threshold parameter is transformed into the percentile parameter. Note that unlike in Seo (2006), it is unnecessary to assume a fixed threshold value that vanishes asymptotically. ${ }^{4}$

In this paper, we will consider a single equation threshold version of the threshold ADL cointegration test. If the variable $x_{2 t}$ in Eq. (2b) is weakly exogenous, it is necessary to add $\Delta x_{2 t}$ as a regressor in the equation describing the conditional expectation of $\Delta x_{1 t}$ given $\Delta x_{2 t}$. Then, we can consider the following conditional model in a single equation testing regression:

$\Delta x 1 t=\left[\alpha_{11} x 1, t-1+\alpha_{12}^{\prime} x 2, t-1+\phi_{11}^{\prime} d t+\phi_{12}^{\prime} s t+\phi_{13}^{\prime} \Delta x 2 f\right] / 1 t+\left[\beta_{11} x 1, t-1+\beta_{12}^{\prime} x 2, t-1+\gamma_{11}^{\prime} d t+\gamma_{12}^{\prime} s t+\gamma_{13}^{\prime} \Delta x 2 t\right.$ ]$/ 2 t+u 1 t . \Delta \mathrm{x} 1 \mathrm{t}=\left[\alpha 11 \times 1, \mathrm{t}-1+\alpha^{\prime} 12 \times 2, \mathrm{t}-1+\phi^{\prime} 11 \mathrm{dt}+\phi^{\prime} 12 \mathrm{st}+\phi^{\prime} 13 \Delta \mathrm{x} 2 \mathrm{t}\right] 11 \mathrm{t}+\left[\beta 11 \mathrm{x} 1, \mathrm{t}-1+\beta^{\prime} 12 \mathrm{x} 2, \mathrm{t}-1+\gamma^{\prime} 11 \mathrm{~d}\right.$ $\left.t+\gamma^{\prime} 12 s t+\gamma^{\prime} 13 \Delta x 2 t\right] 12 t+u 1 t$.

We consider the following hypotheses for the null $\left(\mathrm{H}_{0}\right)$ of no cointegration against the alternative $\left(\mathrm{H}_{\mathrm{a}}\right)$ of cointegration in at least one regime:

equation(5a)

$(A D L) H_{0}: \alpha_{11}=\beta_{11}=0$ against $H_{\mathrm{a}}: \alpha_{11}<0$ or $\beta_{11}<0$ or both ADLH0: $\alpha 11=\beta 11=0$ againstHa: $\alpha 11<0$ or $\beta 11<0$ or both

$$
\begin{gathered}
\left(\text { ADL2) } H_{0}: \alpha_{11}=\beta_{11}=\alpha_{12}=\beta_{12}=0\right. \text { against } \\
H_{\mathrm{a}}: \alpha_{11}<0, \beta_{11}<0, \alpha_{12}<0, \text { or } \beta_{12}<0 .
\end{gathered}
$$

Note that Eq. (5b) imposes the additional restriction that the coefficients of $x_{2, t-1}$ equal zero, as advocated by Boswijk (1994) for ADL linear cointegration models.

Throughout, we adopt instrumental variables (IV) estimation to avoid nuisance parameter problems. We begin with the simplest case where the value of the threshold parameter $(T)$ is known. Consider the stationary instruments, $w_{i t}$, defined as:

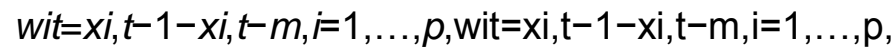

where $m$ is a finite number, $m \ll T$. Clearly, $w_{i t}$ is stationary whether or not the model is cointegrated. For instance, $w_{i t}=\left(x_{i, t-1}-x_{i, t-2}\right)+\ldots+\left(x_{i, t-m+1}-x_{i, t-m}\right)=\Delta x_{i, t-1}+\ldots+\Delta x_{i, t-m+1}$, where each term in the summation is stationary, even if $x_{i t}$ is $/(1)$. We use $w_{i t}$ as an instrument for $x_{i, t-1}$, since these two variables are correlated (under the null and alternative) while $w_{i t}$ is uncorrelated with $u_{i t}{ }^{5}$ Specifically, to estimate Eq. (4), we employ a set of stationary instruments $\left(w_{1 t} l_{1 t}, w_{1 t} l_{2 t}, w_{2 t} l_{1 t}, w_{2 t} l_{2 t}\right)$ for the $l(1)$ regressors $\left(x_{1, t-1} l_{1 t}, x_{1, t-1} l_{2 t}, x_{2, t-1} l_{1 t}, x_{2, t-1} l_{2 t}\right)$.

For brevity, we rewrite Eq. (4) in the general form: 


$$
\begin{aligned}
\Delta x_{1 t} & =z_{1 t}^{\prime} \alpha+z_{2 t}^{\prime} \beta+q_{1 t}^{\prime} \phi+q_{2 t}^{\prime} \gamma+u_{1 t} \\
& =z_{t}^{\prime} \theta+q_{t}^{\prime} b+u_{1 t},
\end{aligned}
$$

where $\theta=\left(\alpha^{\prime}, \beta^{\prime}\right)^{\prime}$ and $b=\left(\phi^{\prime}, \gamma^{\prime}\right)^{\prime}$. Eq. (7) contains two subsets of variables $\left(z_{t}, q_{t}\right)$, where $z_{t}$ is the set of lagged $l(1)$ variables to be instrumented and $q_{t}$ is the remaining set of regressors, including any deterministic terms, lagged differences, and stationary covariates in the testing regression (4). Each of $z_{t}$ and $q_{t}$ can be decomposed into the terms operable in each regime; that is, $z_{t}=\left(z_{1 t}, z_{2 t}^{\prime}\right)^{\prime}$ with $z_{1 t}=\left(x_{1, t-1} l_{1 t}, x_{2, t-1} l_{1 t}\right)$ and $z_{2 t}=\left(x_{1, t-1} l_{2 t}, x_{2, t-1}{ }^{\prime} l_{2 t}\right)^{\prime}$, and $q_{t}=\left(q_{1 t}^{\prime}, q_{2 t}^{\prime}\right)^{\prime}$ with $q_{1 t}=\left(d_{t}^{\prime} l_{1 \mathrm{t}}, s_{t}^{\prime} l_{1 \mathrm{t}}, \Delta x_{2 t} t_{1 \mathrm{t}}\right)^{\prime}$ and $q_{2 t}=\left(d_{t}^{\prime} l_{2 \mathrm{t}}, s_{t}^{\prime} l_{2 \mathrm{t}}, \Delta x_{2 t} l_{2 t}\right)^{\prime}$, respectively.

We can use the simplified expressions in Eq. (7) controlling for the effect of $q_{t}$ to examine the parameter $\theta$. The effect of $q_{t}$ can be easily controlled for by using the residuals from the regression of $x_{t}$ on $q_{t}$. Letting $z=\left(z_{m+1}, \ldots, z_{T}\right)^{\prime}$ and $q=\left(q_{m+1}, \ldots, q_{T}\right)^{\prime}$, we obtain the residuals as $\tilde{z} z^{\sim}=M_{q} z$, where $M_{q}$ is the projection onto the orthogonal space of $q_{t}$ with $M_{q}=I_{T-m}-q\left(q^{\prime} q\right)^{-1} q^{\prime}$. Similarly, we obtain the residuals $\tilde{w^{\prime}} \mathrm{W}^{\sim}=M_{q} w$, where $w=\left(w_{m+1}, \ldots, w_{T}\right)^{\prime}$. Then, we can use $\tilde{w} \mathrm{w}^{\sim}$ with $\tilde{w}_{t \mathrm{w}^{\tilde{t}} \mathrm{t}}=\left(\tilde{w}_{1 t \mathrm{w} \sim 1 \mathrm{t}} t_{1 t}, \tilde{w}_{1 t \mathrm{w} \sim 1 \mathrm{t}} t_{2 t}, \tilde{w}_{2 t} \mathrm{w}^{\sim} 2 \mathrm{t} t_{1 t}, \tilde{w}_{2 t} \mathrm{w}^{2} 2 \mathrm{t} / t_{2 t}\right)^{\prime}$ as the instruments for $\tilde{z} z^{\sim}$. It is important to notice that the deterministic terms and stationary covariates in $q_{t}=\left(d_{t}, s_{t}\right)$ contain lower order terms $O_{p}\left(T^{1 / 2}\right)$ that vanish asymptotically. We let $\xi_{t}=\left(\xi_{1 t}, \ldots, \xi_{p t}\right)^{\prime}$ with $\xi_{i t}=u_{i, t-1}+\ldots+u_{i, t-m}$. Specifically, the following results hold under the null:

$$
\begin{aligned}
& T^{-1 / 2}\left[\sum_{t=m+1}^{T} \tilde{w}_{1 t} u_{1 t}, \ldots, \sum_{t=m+1}^{T} \tilde{w}_{p t} u_{1 t}\right]^{\prime} \\
& =T^{-1 / 2}\left[\sum_{t=m+1}^{T} \xi_{1 t} u_{1 t}, \ldots, \sum_{t=m+1}^{T} \xi_{p t} u_{1 t}\right]^{\prime}+o_{p}(1)
\end{aligned}
$$

(9)

$$
T^{-1} \sum_{t=m+1}^{T} \tilde{w}_{t} \tilde{w}_{t}^{\prime}=T^{-1} \sum_{t=m+1}^{T} \xi_{t} \xi_{t}^{\prime}+o_{p}(1)
$$

Note that the stationary covariates do not affect the asymptotic distribution of the test statistic, since they are simply the element of $q_{t}$ that enters the second terms in Eqs. (8) and (9). Instead, as in Hansen (1995), adding the stationary covariates $s_{t}$ to the testing regression reduces the variance of the estimated residuals, implying an increase in power. By including stationary covariates our IV tests gain power without affecting the standard null distributions. ${ }^{6}$ If $q_{t}=\left(d_{t}, s_{t}\right)$ includes the usual trend, or higher order trends, the estimated coefficients will be properly normalized and have standard normal distributions. 
To estimate Eq. (7) we can use the 2SLS estimator in the usual software packages. The following Wald statistic can be considered to test the null hypothesis (5a) and (5b):

equation(10)

Wald $=(R \hat{\theta})^{\prime}\left[\hat{\sigma}_{1}^{1} R(\tilde{z} \tilde{w})^{-1}\left(\tilde{w}^{\prime} \tilde{w}\right)\left(\tilde{w}^{\prime} \tilde{z}\right)^{-1} R^{\prime}\right]^{-1}(R \hat{\theta})$,

where $\hat{\sigma}_{1 \sigma^{\wedge} 12}^{2}$ is the estimated error variance from Eq. (4), and $R$ is a selection matrix to impose the restrictions under the null hypothesis (5a) and (5b). We denote the Wald statistics from Eq. (10) as $A D L^{\square}$ and $A D L 2^{\square}$ to test the null hypotheses in Eqs. (5a) and (5b), respectively.

Theorem 1. Suppose that $\alpha_{1 j}=\beta_{1 j}=0, j=1,2$, in the data generating process in Eq.(4)and the threshold parameter $\mathrm{T}$ is known. Then, for each of the null hypotheses in Eqs.

(5a) and (5b)under Assumption 1, as $T \rightarrow \infty$, the Wald statistic given in Eq.(10)follows

Wald $\rightarrow \chi_{r}^{2}$,

where $r$ is the number of restrictions on $\alpha_{1 j}$ and $\beta_{1 j}, j=1,2$, and $t$-stat $\left(\alpha_{1 j}\right) \rightarrow Z$ and $t$-stat $\left(\beta_{1 j}\right) \rightarrow Z$.

Proof. See appendix of Enders et al. (2009).

Theorem 1 implies that the asymptotic distributions of the Wald statistics $A D L^{\natural}$ and $A D L 2^{\natural}$ are free of nuisance parameters. Specifically, the limiting distributions of the Wald statistics and $t$ statistics do not depend on the linear deterministic terms $d_{t}$, the number of regressors, and, more importantly, the presence of any stationary covariates, $s_{t}$. Thus, the results for the linear IV cointegration tests of Enders et al. (2009) are extended to the nonlinear threshold tests. Therefore, statistical inference tests for threshold cointegration and nonlinearity can all be conducted using standard distribution theory. ${ }^{7}$ This property is in sharp contrast to the tests using OLS estimation. Note also that the distribution of the Wald statistic does not depend on the threshold indicator function $h_{t}$ or the threshold parameter $T$. Thus, the threshold variable can be any $I(1)$ or $I(0)$ variable or combination of variables. Whereas previous papers on threshold cointegration rely on the error correction term or its first difference to serve as the threshold variable, we can also model the threshold function in more flexible forms. For example, when we estimate the Taylor rule in Section 3, we let the threshold parameter depend on a weighted average of the past inflation rate and the output gap.

\subsection{IV tests with an unknown threshold}

In the above, we have assumed that the threshold parameter $T$ is given or known to the researcher. However, if $t$ is unknown and must be estimated, then the relevant test statistic for our cointegration test depends on whether or not a threshold value is identified under the null hypothesis. To explain, note that under the null hypothesis in Eqs. (5a) and (5b), the threshold parameter is not identified if $\phi=\gamma$ in Eq. (7). In such cases, the well-known Davies (1987) problem will occur if nonlinearity is confined to the cointegrating terms. However, if $\phi \neq \gamma, a$ 
threshold parameter $t$ can be identified regardless of whether the null hypothesis of no cointegration holds in Eqs. (5a) and (5b). Hence, we have two cases to consider that we summarize by the following condition:

Condition 1. In Eq. (7), $\phi=\gamma$.

Note that Condition 1 requires a strong assumption that the corresponding parameters in $\phi$ and $\gamma$ should be identical in each regime. If any of the parameter values of $\phi$ and $\gamma$ are significantly different, this condition is not satisfied. In contrast, if Condition $\mathbf{1}$ does not hold, then the model is a threshold process under the null and alternative hypothesis. Given that the threshold parameter must be estimated, the Wald statistic in Eq. (10) can be defined as:

equation(11)

$\operatorname{Wald}(\hat{\tau})=(R \hat{\theta}(\hat{\tau}))^{\prime}\left[\hat{\sigma}_{1}^{2} R\left(\tilde{z}^{* \prime} \tilde{w}^{*}\right)^{-1}\left(\tilde{w}^{* \prime} \tilde{w}^{*}\right)\left(\tilde{w}^{* \prime} \tilde{z}^{*}\right)^{-1} R^{\prime}\right]^{-1}(R \hat{\theta}(\hat{\tau}))$,

where $\hat{\tau}_{\mathrm{T}^{\wedge}}$ is the estimated threshold parameter, $\tilde{z}^{*}=\tilde{z}(\tilde{\tau})_{\mathrm{Z}^{* *}=\mathrm{Z}^{\tilde{T}}}$ and $\tilde{w}^{*}=\tilde{w}(\hat{\tau})$ $\mathrm{W}^{\sim *}=\mathrm{W}^{\tilde{T^{\wedge}}}$. Thus, in Eq. (2c), we replace $I_{1 t}=I\left(h_{t}>T\right)$ with $I_{1 t}\left(\hat{\tau}_{\mathrm{T}^{\wedge}}\right)=I\left(h_{t}>\hat{\tau}_{\mathrm{T}^{\wedge}}\right)$, and $I_{2 t}(\hat{\tau})$ $\mathrm{T}^{\wedge}=1-I_{1 t}\left(\hat{\tau}_{\mathrm{T}^{\wedge}}\right)$. As in Eqs. (3a)-(3b), the estimate of the threshold parameter is transformed into a percentile of the threshold variable.

To find the asymptotic distribution of Wald $\left(\hat{\tau}_{\mathrm{T}^{\wedge}}\right)$ in Eq. (11), we retain Assumption 1 and, in Appendix A, show that ${ }^{8}$ :

Theorem 2. Suppose that $\alpha_{1 j}=\beta_{1 j}=0, j=1$, 2, in the data generating process in Eq.(4), and the threshold parameter $\mathrm{T}$ is unknown. Then, for each of the null hypotheses in Eqs.

(5a) and (5b) under Assumption 1, as $T \rightarrow \infty$,

If Condition 1 holds such that $\phi=\gamma$, the Wald $\left(\hat{\tau}_{\mathrm{T}^{\wedge}}\right)$ in Eq.(11)has a nonstandard distribution as given in Eq. (A.15) ofAppendix $A$.

(b)

If Condition 1 does not hold such that $\phi \neq \gamma$, the Wald $\left(\hat{\tau}_{\mathrm{T}^{\wedge}}\right)$ in Eq.(11)approaches the same chisquare distribution as the Wald statistic in Eq.(10)with a known threshold parameter $T$.

Proof. See Appendix A.

The key point is that if Condition 1 does not hold, $T$ can be consistently estimated under the null hypothesis of no cointegration and the Davies (1987) problem will not occur. This outcome occurs in partial stability models where a subset of parameters is allowed to differ, regardless of whether the persistence parameters differ in each regime. This outcome can occur, for example, if there are shifts in the mean and/or different short-run dynamics in different regimes. Then, when $\phi \neq \gamma$, and following Shin and Lee (2003), we obtain the result that $\hat{\tau}_{\mathrm{T}^{\wedge}}$ is a consistent 
estimator of $\tau$ where $T\left(\hat{\tau}_{\mathrm{T}^{\wedge}}-\tau\right)=O_{\mathrm{p}}(1)$. In rare cases when Condition 1 holds, the Wald $\left(\hat{\tau}_{\mathrm{T}^{\wedge}}\right)$ in Eq. (11) will no longer have a standard distribution. This outcome is described by the wellknown Davies (1987) problem involving an unidentified nuisance parameter, and the asymptotic distribution of Wald $\left(\hat{\tau}_{\mathrm{T}^{\wedge}}\right)$ in Eq. (11) will no longer be chi-square. In such cases, following Davies (1987) and numerous other papers, we can tabulate bounds for the critical values of a supreme type statistic. We call this statistic SupWald, where

$P[\operatorname{Wald}(\hat{\tau})>\kappa] \leq P[\operatorname{SupWald}(\hat{\tau})>\kappa]$.

$\hat{\tau}_{\mathrm{T}^{\wedge}}$ is estimated by identifying the value where the Wald statistic is maximized, or equivalently where the sum of squared residuals is minimized. Note that the asymptotic distribution of SupWald will not depend on any other nuisance parameters, unlike in the corresponding OLSbased tests; it is simply the order statistic of a chi-square distribution with a particular degree of freedom. ${ }^{9}$ The critical values of the SupWald test are provided in Table 1 for two different sets of trimming values over the search interval for the threshold parameter: $\left(c_{1}, c_{2}\right)=[0.15,0.85]$ and $\left(c_{1}, c_{2}\right)=[0.10,0.90] .^{10}$

Table 1

Gritical values of SupWald.

\begin{tabular}{llllll}
\hline$d f$ & $c_{1}$ & $c_{2}$ & $10 \%$ & $5 \%$ & $1 \%$ \\
\hline 1 & 0.15 & 0.85 & 14.40 & 15.77 & 18.92 \\
& 0.10 & 0.90 & 14.61 & 15.98 & 19.13 \\
2 & 0.15 & 0.85 & 17.58 & 19.05 & 22.29 \\
& 0.10 & 0.90 & 17.87 & 19.30 & 22.46 \\
3 & 0.15 & 0.85 & 20.26 & 21.75 & 25.19 \\
& 0.10 & 0.90 & 20.54 & 22.05 & 25.51 \\
4 & 0.15 & 0.85 & 22.67 & 24.20 & 27.69 \\
& 0.10 & 0.90 & 22.93 & 24.51 & 28.04 \\
5 & 0.15 & 0.85 & 24.86 & 26.46 & 30.17 \\
& 0.10 & 0.90 & 25.17 & 26.76 & 30.44 \\
6 & 0.15 & 0.85 & 26.91 & 28.58 & 32.36 \\
& 0.10 & 0.90 & 27.24 & 28.91 & 32.57 \\
7 & 0.15 & 0.85 & 28.91 & 30.61 & 34.34 \\
& 0.10 & 0.90 & 29.23 & 30.94 & 34.82 \\
8 & 0.15 & 0.85 & 30.86 & 32.66 & 36.58 \\
& 0.10 & 0.90 & 31.24 & 32.96 & 36.83 \\
9 & 0.15 & 0.85 & 32.69 & 34.53 & 38.47 \\
& 0.10 & 0.90 & 33.06 & 34.85 & 38.78 \\
10 & 0.15 & 0.85 & 34.54 & 36.37 & 40.30 \\
& 0.10 & 0.90 & 34.87 & 36.67 & 40.76 \\
11 & 0.15 & 0.85 & 36.35 & 38.21 & 42.35 \\
& 0.10 & 0.90 & 36.67 & 38.56 & 42.60 \\
12 & 0.15 & 0.85 & 38.08 & 39.97 & 44.28 \\
& 0.10 & 0.90 & 38.41 & 40.30 & 44.62 \\
\hline \multirow{2}{*}{15} & & & &
\end{tabular}

Note: These critical values of SupWald are based on the sample size $T=1000$ obtained using 100,000 replications. Here, $c_{b} i=1,2$, are the pre-specified values of the empirical percentile of $t$ and $d f$ is the number of restrictions.

Since a researcher may not know if Condition 1 holds in the data generating process (DGP), it might be tempting to take a conservative approach and use the wide confidence intervals 
provided by the SupWald critical values in Table 1 (instead of the values from a $X^{2}$ table). However, it is important to note that while we include the SupWald test for completeness we recommend against its use in empirical applications. To explain, it is easy to over-fit the data with a nonlinear model, and we strongly agree with those cautioning against estimating a nonlinear model unless there are compelling reasons to do so.

Hence, there is a caveat to our claim that the IV tests are invariant to nuisance parameters. Our test does not enable the researcher to distinguish whether Condition $\mathbf{1}$ holds and the appropriate critical values for the SupWald test will depend on the difference between $\phi$ and $\gamma$. As such, the magnitude of $|\phi-\gamma|$ becomes a nuisance parameter for the SupWald test and the test statistic diverges asymptotically as the difference between $\phi$ and $\gamma$ increases in the DGP. ${ }^{11}$ The point is that the SupWald test is not a test for linear versus nonlinear adjustment.

\subsection{Finite sample performance}

In order to examine the small-sample properties of our test, we perform several Monte Carlo experiments using the DGP:

$$
\begin{aligned}
& \Delta x_{1 t}=\varphi^{\prime} \Delta x_{2 t}+\delta\left(x_{1 t-1}-d_{t-1}-\beta^{\prime} x_{2 t-1}\right)+\psi s_{t}+v_{t}, \\
& \Delta x_{2 t}=u_{t}, \\
& s_{t}=\rho s_{t-1}+\varepsilon_{t},
\end{aligned}
$$

where $v_{t} \sim N\left(0, \sigma_{v}{ }^{2}\right), u_{t} \sim N\left(0, \sigma_{u}{ }^{2}\right)$, and $\varepsilon_{t} \sim N\left(0, \sigma_{\varepsilon}{ }^{2}\right)$. This DGP is similar to that in Kremers et al. (1992), except that we explicitly include the stationary covariate $s_{t}$. Notice that $\rho$ captures the persistence of the stationary covariates and that $\delta$ indicates the strength of the cointegrating relationship. Under the null of no cointegration, $\delta=0$ and under the alternative, $\delta<0$. In order to conserve space, we report simulation results for 5000 Monte Carlo replications using $\rho=0.9$, $T=100$, and $\delta=[0,-0.1]$. We report the size and power of our tests using the asymptotic chisquare distribution at the $5 \%$ significance level. The value of $m$ is selected to minimize the sum of squared residuals.

We consider four indicators with different threshold variables: $h_{t-1}, \Delta h_{t-1}, l(1)$ and $l(0)$. The variables $h_{t-1}$ and $\Delta h_{t-1}$ capture asymmetric level and momentum threshold effects, respectively, using the residuals (in differences) from the cointegrating regression in levels, $x_{1 t}-\beta x_{2 t} . I(1)$ and $I(0)$ represent any arbitrary independent $I(1)$ or $I(0)$ threshold variable from inside or outside the model. In our simulations, we use the median value of the threshold variable as the threshold parameter. To examine the effect of using different signal-noise ratios, we set $\sigma_{v}{ }^{2}=1, \theta=1$, and consider different values of $\sigma_{u}$. We consider the cases of $(\varphi$, $\left.\sigma_{u}\right)=(1.0,1),(0.5,6)$, and $(0.5,16)$, respectively.

The simulation results for $A D L^{\square}$ and $A D L 2^{\square}$ are displayed in Table 2. We begin by examining the results in Panel $A$, where the stationary covariate $s_{t}$ is omitted. It is clear that all of the IV threshold cointegration tests are invariant to the signal-noise ratio under the null $\delta=0$. Although 
the tests show a mild negative size distortion (under rejections), except with the $/(1)$ threshold variable, overall, the tests have reasonable size properties with virtually no over rejections. It is important to note that the power increases dramatically as the signal-noise ratio increases. The intuition is clear: the contemporaneous regressor $\Delta x_{2 t}$ in Eq. (12) acts as a stationary covariate and the power increases as the signal-noise ratio increases. This phenomenon can be explained in the same spirit as when adding stationary covariates to unit root tests as described by Hansen (1995). However, while the OLS-based unit root or cointegration test with stationary covariates has a nuisance parameter problem under the null, the IV based tests do not entail this problem. ${ }^{12}$ In contrast, in the IV based tests the size properties under the null are unaffected by including $\Delta x_{2 t}$ or stationary covariates, and the power increases significantly under the alternative. Moreover, while it can be difficult to find desirable stationary covariates in unit root tests, this is not the case here, since $\Delta x_{2 t}$ is naturally included in the testing regression and acts a stationary covariate. While the size and power properties differ somewhat depending on the threshold variable, the differences are small. 
Table 2

Size and power of IV threshold cointegration tests.

\begin{tabular}{|c|c|c|c|c|c|c|}
\hline \multicolumn{7}{|c|}{ Panel A. Without the stationary covariate $s_{t}$} \\
\hline \multirow[t]{2}{*}{$I_{t}$} & \multirow[t]{2}{*}{$\left(\varphi, \sigma_{u}\right)$} & \multicolumn{3}{|c|}{ Size $(\delta=0)$} & \multicolumn{2}{|c|}{ Power $(\delta=-0.1)$} \\
\hline & & & $A D L^{*}$ & $\operatorname{ADC} 2^{*}$ & $A D L^{*}$ & $A D L 22^{*}$ \\
\hline \multirow[t]{3}{*}{$\Delta h_{t-1}$} & $(1,1)$ & & 0.024 & 0.018 & 0.113 & 0.109 \\
\hline & $(.5,6)$ & & 0.024 & 0.018 & 0.625 & 0.890 \\
\hline & $(.5,16)$ & & 0.024 & 0.018 & 0.947 & 1.000 \\
\hline \multirow[t]{3}{*}{$h_{t-1}$} & $(1,1)$ & & 0.012 & 0.008 & 0.031 & 0.014 \\
\hline & $(.5,6)$ & & 0.012 & 0.008 & 0.290 & 0.675 \\
\hline & $(.5,16)$ & & 0.012 & 0.008 & 0.892 & 0.998 \\
\hline \multirow[t]{3}{*}{$I(0)$} & $(1,1)$ & & 0.025 & 0.019 & 0.117 & 0.066 \\
\hline & $(5,6)$ & & 0.025 & 0.019 & 0.653 & 0.899 \\
\hline & $(.5,16)$ & & 0.025 & 0.019 & 0.951 & 1.000 \\
\hline \multirow[t]{3}{*}{$I(1)$} & $(1,1)$ & & 0.051 & 0.032 & 0.173 & 0.096 \\
\hline & $(5,6)$ & & 0.051 & 0.032 & 0.612 & 0.884 \\
\hline & $(5,16)$ & & 0.051 & 0.032 & 0.945 & 1.000 \\
\hline \multicolumn{7}{|c|}{ Panel B. With the stationary covariate $s_{t}$} \\
\hline \multirow[b]{2}{*}{$I_{t}$} & \multirow[b]{2}{*}{$\left(\varphi, \sigma_{u}\right)$} & \multirow[b]{2}{*}{$\psi$} & \multicolumn{2}{|c|}{ Size $(\delta=0)$} & \multicolumn{2}{|c|}{ Power $(\delta=-0.1)$} \\
\hline & & & $A D L^{*}$ & $A D 12^{*}$ & $A D L^{*}$ & $A D L 2^{*}$ \\
\hline \multirow[t]{6}{*}{$\Delta h_{t-1}$} & $(1,1)$ & 1 & 0.012 & 0.011 & 0.657 & 0.773 \\
\hline & $(.5,6)$ & & & & 0.768 & 0.900 \\
\hline & $(.5,16)$ & & & & 0.939 & 0.998 \\
\hline & $(1,1)$ & 3 & 0.014 & 0.010 & 0.967 & 0.991 \\
\hline & $(.5,6)$ & & & & 0.972 & 0.993 \\
\hline & $(.5,16)$ & & & & 0.979 & 0.997 \\
\hline \multirow{6}{*}{$\Delta h_{t-1}$} & $(1,1)$ & 1 & 0.012 & 0.011 & 0.558 & 0.604 \\
\hline & $(.5,6)$ & & & & 0.641 & 0.787 \\
\hline & $(.5,16)$ & & & & 0.907 & 0.995 \\
\hline & $(1,1)$ & 3 & 0.013 & 0.009 & 0.965 & 0.990 \\
\hline & $(.5,6)$ & & & & 0.967 & 0.991 \\
\hline & $(.5,16)$ & & & & 0.976 & 0.998 \\
\hline \multirow[t]{6}{*}{$I(0)$} & $(1,1)$ & 1 & 0.014 & 0.014 & 0.670 & 0.741 \\
\hline & $(.5,6)$ & & & & 0.788 & 0.907 \\
\hline & $(.5,16)$ & & & & 0.945 & 0.999 \\
\hline & $(1,1)$ & 3 & 0.014 & 0.012 & 0.972 & 0.993 \\
\hline & $(.5,6)$ & & & & 0.974 & 0.993 \\
\hline & $(.5,16)$ & & & & 0.984 & 0.999 \\
\hline \multirow[t]{6}{*}{$I(1)$} & $(1,1)$ & 1 & 0.015 & 0.013 & 0.462 & 0.384 \\
\hline & $(.5,6)$ & & & & 0.755 & 0.892 \\
\hline & $(.5,16)$ & & & & 0.954 & 0.999 \\
\hline & $(1,1)$ & 3 & 0.013 & 0.011 & 0.940 & 0.955 \\
\hline & $(.5,6)$ & & & & 0.953 & 0.976 \\
\hline & $(.5,16)$ & & & & 0.978 & 0.998 \\
\hline
\end{tabular}

In Panel B of Table 2, we examine the effect of explicitly including the stationary covariate variable $s_{t}$ in the testing regression. The results under the null differ little from those in Panel A. We still observe (somewhat greater) negative size distortions under the null, but with no over rejections. The sizes are again unaffected by the signal-noise ratio. In particular, the sizes do not depend on the values of $\rho$ and $\psi$ in Eq. (12) that describe the stationary covariates. Most important, the power increases when the stationary covariate $s_{t}$ is included, and increases monotonically as the value of $\psi$ increases and/or as the signal-noise ratio increases. Again, the size properties are virtually the same regardless of the threshold variable that is adopted. 


\section{EMPIRICAL RESULTS}

To estimate a Taylor rule in the form of Eq. (1), we obtained monthly observations of the federal funds rate from the Federal Reserve Bank of St. Louis' data base FRED II (http://research.stlouisfed.org/fred2/). Unlike interest rates, price and output data can be subject to substantial revisions. As pointed out by Orphanides (2001), to best ascertain the behavior of the Federal Reserve it is necessary to use the data actually available to the Fed at the time their decisions are made. As such, we obtained real-time data on real output and the output price index, $p_{t}$, from the Philadelphia Federal Reserve Bank's website.

Since the output and price data is reported quarterly and the interest rate data is reported monthly, we use the quarterly average of the federal funds rate as the dependent variable $i_{t}$. We follow standard practice and construct an inflation measure, $\pi_{t}$, as the average inflation rate over the past year. Specifically,

$\pi t=100(\operatorname{Inpt}-\operatorname{Inpt}-4), \pi \mathrm{t}=100 \operatorname{lnpt}-\operatorname{Inpt}-4$,

where all values of $p_{t-i}$ are the real-time price indices for time period $t-i$ reported at time period $t$.

Several different methods have been proposed to measure the output gap, $y_{t}$. Since we use the data set originally constructed by Croushore and Stark (2001), we adopt their methodology and filter the real output data with an HP filter. As indicated in Croushore and Stark (2001), our aim is not to ascertain the way that real output evolves over the long-run. Instead, the goal is to obtain a reasonable measure of the pressure felt by the Federal Reserve to use monetary policy to affect the level of output. Since we use real-time data, we first HP filter the entire real-time output series available for each time period $t$. We construct $y_{t}$ as the percentage difference between the values of real-time output and the HP filtered output. ${ }^{13}$

\subsection{Results using linear models}

We first examine the Taylor rule in a linear framework. In Table 3, we report estimates of the Taylor rule for five sample periods often examined in the literature. The 1970:1-1979:2 period represents the tenure of William Martin, Arthur Burns and G. William Miller as Federal Reserve chairmen. The so-called Volcker-Greenspan period spanned 1979:4-2005:4. A number of empirical papers omit the first few years of this period since the Fed experimented with money base targeting in the early part of the Volcker period. The pure Greenspan period begins in 1987:4 and ends in 2005:4. 
Table 3

Estimates of the linear Taylor rule for selected sample periods.

\begin{tabular}{lccccc}
\hline Sample period & $\alpha_{0}$ & $\pi_{t}$ & $y_{t}$ & $i_{t-1}$ & $i_{t-2}$ \\
\hline 1970:1-2005:4 & -0.165 & 0.213 & 0.297 & 0.901 & \\
(Full sample) & $(-0.883)$ & $(4.286)$ & $(6.102)$ & $(27.324)$ & \\
1970:1-1979:2 & -0.527 & 0.124 & 0.324 & 0.985 & \\
(Martin-Burns-Miller) & $(-0.854)$ & $(1.013)$ & $(4.392)$ & $(9.443)$ & \\
1979:4-2005:4 & -0.137 & 0.537 & 0.350 & 0.760 & \\
(Volcker-Greenspan) & $(-0.750)$ & $(6.297)$ & $(5.169)$ & $(17.669)$ & \\
1983:1-2005:4 & 0.010 & 0.178 & 0.151 & 1.285 & -0.377 \\
(Volcker-Greenspan: post & $(0.083)$ & $(2.756)$ & $(3.760)$ & $(13.905)$ & $(-4.284)$ \\
$\quad$ money base targeting) & & & & & \\
1987:4-2005:4 & -0.121 & 0.137 & 0.209 & 1.354 & -0.396 \\
(Greenspan period) & $(-0.998)$ & $(2.383)$ & $(4.223)$ & $(12.643)$ & $(-3.692)$ \\
\hline
\end{tabular}

Notes: The $t$-statistics are in parentheses. We eliminated lagged values of $i_{t-i}$ if they were not significant at the $10 \%$ level.

There are several important issues to note about the estimates shown in Table 3. For all time periods, the estimated coefficients on $\pi_{t}$ and $y_{t}$ are positive and usually significant at conventional levels. However, there are some problems with the estimates that might be dubbed "Some unpleasant Taylor rule arithmetic." Specifically:

- The coefficients, or the sum of the coefficients, on the lagged federal funds rate are all quite large. Although this is often referred to as 'interest rate smoothing,' the amount of smoothing seems excessive. In fact, the estimates are close enough to unity to suggest the possibility of a unit root in the federal funds rate. Of course, it could also be argued that $i_{t}, \pi_{t}$ and $y_{t}$ are jointly endogenous variables so that GMM estimation is preferable to OLS estimation. Nevertheless, there are several other problems that are unlikely to be resolved by GMM estimation.

- As shown in Table 4, diagnostic checking indicates that the interest rate and inflation variables act as unit root processes. Specifically, Dickey-Fuller tests indicate that for all sample periods ending in 2005:4 it is not possible to reject the null hypothesis of a unit root plus drift (against an alternative of stationary about a fixed mean) in either $i_{t}$ or $\pi_{t}$. When intercepts are included in the unit root test equations, the output gap appears to be stationary over the entire sample period, but it is not clear whether $y_{t}$ acts as a stationary process during the 1970:1-1979:2 and 1987:4-2005:4 sub-periods. A wellknown problem of the Dickey-Fuller test is that it loses power in the presence of deterministic regressors in the estimating equation that are not in the data generating process. For all sample periods under consideration, the HP filtered output gap had a mean near zero. Moreover, the intercepts in the Dickey-Fuller $\tau_{\mu}$ test were all insignificant at any conventional significance level. When these insignificant intercept terms were eliminated from the $\tau_{\mu}$ version of the Dickey-Fuller test, the null hypothesis of a unit root in $y_{t}$ could be rejected at the $1 \%$ level in all sub-periods. Therefore, we will proceed with the assumption that $y_{t}$ is stationary in all periods.

- The possibility of nonstationary variables implies that the Taylor rule equation is spurious unless the /(1) variables are cointegrated. Even if the variables turn out to be cointegrated, the distribution of the coefficient estimates obtained by using OLS (or GMM) do not have the usual properties since they multiply nonstationary variables. 
Table 4

Unit root tests of the Taylor rule variables.

\begin{tabular}{lllccc}
\hline Start & End & & $i_{t}$ & $\pi_{t}$ & $y_{t}$ \\
\hline $1970: 1$ & $2005: 4$ & $\rho$ & -0.055 & -0.014 & -0.198 \\
& & $\tau_{\mu}$ & $(-1.922)$ & $(-0.990)$ & $(-5.615)$ \\
$1970: 1$ & $1979: 2$ & $\rho$ & -0.560 & -0.110 & -0.157 \\
& & $\tau_{\mu}$ & $(-3.388)$ & $(-2.558)$ & $(-2.900)$ \\
$1979: 4$ & $2005: 4$ & $\rho$ & -0.044 & -0.032 & -0.227 \\
& & $\tau_{\mu}$ & $(-1.532)$ & $(-2.311)$ & $(-4.052)$ \\
$1983: 1$ & $2005: 4$ & $\rho$ & -0.031 & -0.057 & -0.175 \\
& & $\tau_{\mu}$ & $(-1.711)$ & $(-2.345)$ & $(-4.714)$ \\
$1987: 4$ & $2005: 4$ & $\rho$ & -0.042 & -0.048 & -0.114 \\
& & $\tau_{\mu}$ & $(-2.375)$ & $(-1.519)$ & $(-2.589)$ \\
\hline
\end{tabular}

Note:Ineach case we estimated a model of the general form $\Delta x_{t}=\alpha_{0}+\rho x_{t-1}+\Sigma \alpha \Delta \Delta x_{t-1}+\varepsilon_{\mathrm{p}}$ Lag lengthswerechosen using a maximum lag length $\left(i_{\max }\right)$ of 12 . If the $t$-statistic for the last lag wasnot significant at the $5 \%$ level, $i_{\max }$ was reduced by one and the equation was re-estimated. $\tau_{\mu}$ is the sample value of the $t$-statistic for the null hypothesis $\rho=0$. With 50 (100) observations, the critical values at the $10 \%$ and $5 \%$ significance levels are $-2.60(-2.58)$ and $-2.93(-2.89)$, respectively. When the tests for $y_{t}$ were conducted without the insignificant values of $\alpha_{0}$, the null hypothesis of a unit root could be rejected at the $1 \%$ leved in every case.

Given the above, the first important task is to check for the existence of a cointegrating relationship among the nonstationary variables. Respectively, Table 5 and Table 6 report the results of the Engle-Granger and Johansen linear cointegration tests for the various sample periods. ${ }^{14}$ At conventional significance levels in the Engle-Granger tests, the null hypothesis of no cointegration could not be rejected in any of the sample periods. When we used the Johansen test, the null hypothesis of no cointegration could be rejected only for the VolckerGreenspan period (1979:4-2005:4). In this period, the sample values of $\lambda_{\max }$ and $\lambda_{\text {trace }}$ of 18.50 and 22.13 exceeded the $5 \%$ asymptotic critical values of 15.67 and 19.96 . Nevertheless, the estimated cointegrating relationship is problematic since the long-run relationship is $i_{t}=-59.666+29.092 \pi_{t}$ and the speed of adjustment coefficients are both positive. The only evidence of a reasonable cointegrating relationship was for the Greenspan period (1987:42005:4) when we checked for cointegration between $i_{t}, \pi_{t}$ and $y_{t}$. When $y_{t}$ was treated as $l(1)$, the estimated cointegrating relationship for this period is:

$i t=-5.783+4.283 \pi t+6.991 y t$. 
Table 5

Engle-Granger linear cointegration tests.

\begin{tabular}{llllll}
\hline Start & End & $\beta_{0}$ & $\beta_{1}$ & $\rho$ & Lags \\
\hline $1970: 1$ & $2005: 4$ & $2.541(6.622)$ & $1.049(12.490)$ & $-0.105(-2.230)$ & 12 \\
$1979: 4$ & $2005: 4$ & $1.442(4.292)$ & $1.609(18.002)$ & $-0.149(-2.652)$ & 12 \\
$1983: 1$ & $2005: 4$ & $0.930(1.909)$ & $1.811(10.083)$ & $-0.090(-2.026)$ & 9 \\
$1987: 4$ & $2005: 4$ & $1.265(2.320)$ & $1.546(6.958)$ & $-0.090(-2.274)$ & 9 \\
\hline
\end{tabular}

Notes: The $t$-statistics are in parentheses. For each sample period, we estimated a potential long-run equilibrium relationship of the form $i_{t}=\beta_{0}+\beta_{0} \pi_{t}+e_{t}$. The second step was to ue the estimated residuals to estimate an equation of the form $\Delta e_{t}=\rho e_{t-1}+\Sigma \alpha \alpha_{t-1}+v_{t}$ With 50 (100) observations, the critical value at the $10 \%$ and $5 \%$ significance levels are -3.31 $(-3.09)$ and $-3.46(-3.40)$, respectively.

Table 6

Johansen linear cointegration tests.

\begin{tabular}{|c|c|c|c|c|c|c|c|}
\hline Start & End & $\lambda_{\max }$ & $\lambda_{\text {trace }}$ & $\beta_{0}$ & $\beta_{1}$ & $\alpha_{1}$ & $\alpha_{2}$ \\
\hline $1970: 1$ & $2005: 4$ & 9.88 & 14.35 & 4.125 & 0.658 & $-0.101(-2.555)$ & $-0.029(-2.220)$ \\
\hline $1979: 4$ & $2005: 4$ & 18.50 & 22.13 & -59.666 & 29.092 & $0.003(2.476)$ & $0.003(4.215)$ \\
\hline 1983:1 & $2005: 4$ & 4.90 & 6.62 & 2.320 & 1.161 & $-0.050(-2.206)$ & $0.002(0.113)$ \\
\hline $1987: 4$ & $2005: 4$ & 6.88 & 8.82 & 4.100 & 0.151 & $-0.059(-2.609)$ & $-0.009(-0.599)$ \\
\hline
\end{tabular}

With three variables in the potential cointegrating relationship, the sample values of $\lambda_{\max }$ and $\lambda_{\text {trace }}$ of 24.63 and 36.69 exceeded the $5 \%$ asymptotic critical values of 22.00 and 34.91 , respectively. There was no strong evidence of a second cointegrating vector. Inflation and the output gap appear to be weakly exogenous, while the speed of adjustment coefficient for $i_{t}$ was -0.075 with a $t$-statistic of -4.965 . Yet, some would argue with this finding since it is unlikely that $y_{t}$ actually contains a unit root. Still more would be concerned that the sample period contains only 65 observations whereas each equation in the 8-lag VAR has 40 coefficients.

\subsection{Threshold estimation}

We began by estimating a baseline OLS threshold model using Chan's (1993) method to obtain a consistent estimate of the threshold value $\tau$. The form of the baseline model is:

$i t=\left[\alpha_{0}+\alpha_{1} \pi t+\alpha_{2} y t+\alpha_{3} i t-1+\alpha_{4} i t-2\right] / 1 t+\left[\beta_{0}+\beta_{1} \pi t+\beta_{2} y t+\beta_{3} i t-1+\beta_{4} i t-2\right] / 2 t+\varepsilon t, i t=\alpha 0+\alpha 1 \pi t+\alpha 2 y t+\alpha 3 i t-1+\alpha$ $4 i t-211 t+\beta 0+\beta 1 \pi t+\beta 2 y t+\beta 3 i t-1+\beta 4 i t-212 t+\varepsilon t$,

where $I_{1 t}$ is the Heaviside indicator that $I_{1 t}=1$ if $\pi_{t-d}>T$ and $I_{1 t}=0$ otherwise, $I_{2 t}=1-I_{1 t}$; and $d$ is the delay parameter estimated as the integer value of $d=1$ or 2 that results in the smallest residual sum of squares.

The results for all five sample periods are shown in Table 7. In examining the table, note that for all periods except 1970:1-1979:2, the prob-values of Hansen's (1997) threshold test are all strongly supportive of threshold behavior. Consider the estimates for the 1979:4-2005:4 sample period: 
(14)

$$
\begin{aligned}
i_{t}= & {\left[\underset{(3.22)}{6.023}+\underset{(3.92)}{0.588} \pi_{t}+\underset{(5.27)}{1.356} y_{t}+\underset{(5.31)}{0.458} i_{t-1}\right] I_{1 t} } \\
& +\left[\underset{(-4.20)}{-0.088}+\underset{(1.69)}{0.196} \pi_{t}+\underset{(3.61)}{0.232} y_{t}+\underset{(19.59)}{0.977} i_{t-1}\right] I_{2 t},
\end{aligned}
$$

where $d=1$ and $\hat{\tau}_{T^{\wedge}}=5.517$.

Table 7

\begin{tabular}{|c|c|c|c|c|c|}
\hline & Start end & Start end & Start end & Start end & Start end \\
\hline & 1970:1 & 1970: 1 & $1979: 4$ & 1983:1 & $1987: 4$ \\
\hline & $1979: 2$ & $2005: 4$ & $2005: 4$ & $2005: 4$ & $2005: 4$ \\
\hline \multirow[t]{2}{*}{$\alpha_{0}$} & -3.906 & -3.209 & 6.023 & 1.703 & 0.001 \\
\hline & $(-0.899)$ & $(-1.182)$ & (3.223) & $(1.839)$ & $(0,003)$ \\
\hline \multirow[t]{2}{*}{$\beta_{0}$} & -1.097 & -0.162 & -0.088 & -0.048 & 0.026 \\
\hline & $(-3.119)$ & $(-0.986)$ & $(-0.420)$ & $(-0.536)$ & $(0.239)$ \\
\hline \multirow[t]{2}{*}{$I_{1 t^{n}} \pi_{t}$} & 1.928 & 1.188 & 0.588 & 0.931 & 1.041 \\
\hline & (1.947) & (3.744) & (3.916) & (4.955) & (3.239) \\
\hline \multirow[t]{2}{*}{$I_{2 t} \pi_{t}$} & 0.160 & 0.149 & 0.196 & 0.092 & 0.053 \\
\hline & (1.291) & $(2872)$ & (1.692) & (1.578) & $(0.925)$ \\
\hline \multirow[t]{2}{*}{$l_{1 t} y_{t}$} & 1.279 & 1.300 & 1.356 & 0.335 & 0.638 \\
\hline & $(2.471)$ & (8.911) & (5.266) & (5.504) & $(5.148)$ \\
\hline \multirow[t]{2}{*}{$I_{2 t} y_{t}$} & 0.312 & 0.231 & 0.232 & 0.176 & 0.209 \\
\hline & (3.912) & (4.921) & (3.607) & (3.939) & (3.696) \\
\hline \multirow[t]{2}{*}{$I_{1 t} i_{t-1}$} & -0.069 & 0.685 & 0.458 & 0.803 & 0.783 \\
\hline & $(-0.200)$ & (11.594) & (5.309) & (5.197) & (3.724) \\
\hline \multirow{2}{*}{$I_{2 t} i_{t-1}$} & 1.038 & 0.931 & 0.907 & 1.455 & 1.392 \\
\hline & (9.515) & $(27.874)$ & (19.598) & (16.478) & (11.097) \\
\hline \multirow[t]{2}{*}{$I_{1 t} i_{t-2}$} & & & & -0.439 & -0.208 \\
\hline & & & & $(-2.856)$ & $(-1.235)$ \\
\hline \multirow[t]{2}{*}{$I_{2 t} i_{t-2}$} & & & & -0.496 & -0.442 \\
\hline & & & & $(-5.953)$ & $(-3.552)$ \\
\hline$d$ & 2 & 1 & 1 & 1 & 2 \\
\hline$\tau$ & 8.187 & 8.078 & 5.517 & 3.633 & 2.721 \\
\hline prob & 0.144 & 0.017 & 0.001 & 0.000 & 0.024 \\
\hline
\end{tabular}

OLS threshold estimates of the Taylor rule.

Notes: The $t$-statistics are in parentheses, $\tau$ is the threshold value, and prob is the prob-value in Hansen's (1997) test for threshold behavior.

In the threshold model, both the intercept terms and the slope coefficients determine the degree of feedback between $\pi_{t}$ and $i_{t}$. For any given value of $i_{t-1}$, as $\pi_{t-1}$ begins to exceed the threshold value of $5.517, i_{t}$ increases by $(6.023+0.088)+(0.588-0.196) \pi_{t}+(1.356-0.232)$ $y_{t}$. For all values of $\pi_{t}$ and $y_{t}$ in the data set, the increase in $i_{t}$ is sufficient to ensure that $i_{t}-\pi_{t}$ is much greater when $\pi_{t-1} \geq 5.517$ than when $\pi_{t-1}<5.517$. Also notice that there is far more interest rate smoothing when inflation is below the threshold than when it is above the threshold. Overall, the point estimates of the coefficients suggest that the Fed is far more policy active in the high inflation regime than in the low inflation regime. 


\subsection{Estimates with stationary instruments}

Although these results are interesting, the properties of the parameter estimates based on the usual OLS estimation are unknown because the estimated coefficients do not have a standard normal distribution and it is not clear whether the regression equations are spurious. We begin by testing for cointegration using the instruments $I_{1 t}\left(i_{t-1}-i_{t-m}\right), l_{2 t}\left(i_{t-1}-i_{t-m}\right), l_{1 t}\left(\pi_{t-1}-\pi_{t-m}\right)$, and $l_{2 t}\left(\pi_{t-1}-\pi_{t-m}\right)$ for the variables $l_{1} i_{t-1}, l_{2 t} i_{t-1}, l_{t} \pi_{t-1}$, and $l_{2 t} \Pi_{t-1}$, respectively. ${ }^{15}$ As a result, the distributions of $\alpha_{1}, \beta_{1}, \alpha_{2}$, and $\beta_{2}$ are multivariate normal. The assumption that the inflation rate is weakly exogenous means that $l_{1} \Delta \pi_{t}$ and $l_{2} \Delta \pi_{t}$ can be included as additional stationary covariates in the testing regression.

In the ADL version of the test, if we can reject the restriction that $\alpha_{11}=\beta_{11}=0$, it follows that the interest rate and inflation rate are cointegrated. In the ADL2 version of the test, if we reject the null hypothesis that all four values of $\alpha_{11}=\beta_{11}=\alpha_{12}=\beta_{12}=0$, we can conclude that the interest rate and inflation rate are cointegrated. ${ }^{16}$ In the form presented above, the residuals of the two ADL equations had serial correlation; we corrected this problem by using lagged values of the dependent variables. ${ }^{17}$ The estimates for the four sample periods exhibiting threshold behavior are shown in Table 8.

Table 8

IV threshold cointegration estimates of the nonlinear Taylor rule.

\begin{tabular}{|c|c|c|c|c|c|c|c|c|}
\hline & Start end & Start end & Start end & Start end & Start end & Start end & Start end & Start end \\
\hline & 1970:1 & $1979: 4$ & 1983:1 & $1987: 4$ & 1970:1 & $1979: 4$ & 1983:1 & $1987: 4$ \\
\hline & $2005: 4$ & $2005: 4$ & $2005: 4$ & $2005: 4$ & $2005: 4$ & $2005: 4$ & $2005: 4$ & $2005: 4$ \\
\hline & \multicolumn{4}{|c|}{ without $I_{1 t} \Delta \pi_{t}$ and $I_{2 r} \Delta \pi_{t}$} & \multicolumn{4}{|c|}{ with $I_{1}, \Delta \pi_{t}$ and $I_{2}, \Delta \pi_{t}$} \\
\hline \multirow[t]{2}{*}{$I_{1} d t-1$} & -0.129 & -0.623 & -0.221 & -0.181 & -0.134 & -0.718 & -0.302 & -0.811 \\
\hline & $(-1.97)$ & $(-2.43)$ & $(-2.22)$ & $(-1.03)$ & $(-1.77)$ & $(-3.18)$ & $(-2.72)$ & $(-4.98)$ \\
\hline \multirow[t]{2}{*}{$I_{2} t_{t} t=1$} & -0.066 & -0.079 & -0.064 & -0.084 & -0.080 & -0.062 & -0.055 & -0.080 \\
\hline & $(-1.08)$ & $(-2.06)$ & $(-1.93)$ & $(-2.64)$ & $(-2.34)$ & $(-1.64)$ & $(-1.57)$ & $(-2.36)$ \\
\hline \multirow[t]{2}{*}{$I_{1} \pi_{t-1}$} & 0.247 & 1.036 & 0.343 & 0.239 & 0.195 & 1.032 & 0.689 & 1.629 \\
\hline & $(1.58)$ & (3.28) & $(0.98)$ & $(0.63)$ & (1.53) & $(3.43)$ & $(2.21)$ & $(4.13)$ \\
\hline \multirow{2}{*}{$I_{2} \pi_{t-1}$} & -0.001 & -0.099 & -0.015 & -0.010 & -0.067 & 0.047 & 0.050 & 0.010 \\
\hline & $(-0.00)$ & $(-0.46)$ & $(-0.07)$ & $(-0.07)$ & $(-0.33)$ & $(0.17)$ & $(0.24)$ & $(0.06)$ \\
\hline \multirow[t]{2}{*}{$I_{1} y_{t-1}$} & 0.234 & 0.419 & 0.217 & 0.585 & 0.189 & 0.383 & 0.276 & 0.982 \\
\hline & $(2.80)$ & (3.35) & $(3.09)$ & $(2.67)$ & $(1.82)$ & $(2.76)$ & $(3.85)$ & $(6.24)$ \\
\hline \multirow[t]{2}{*}{$I_{2} y_{t-1}$} & 0.339 & 0.337 & 0.323 & 0.367 & 0.343 & 0.289 & 0.301 & 0.354 \\
\hline & $(5.05)$ & $(5.91)$ & $(4.88)$ & $(5.80)$ & $(5.51)$ & $(6.37)$ & $(4.45)$ & $(5.43)$ \\
\hline \multirow[t]{2}{*}{$I_{1} \Delta \pi_{t}$} & & & & & 0.418 & 0.349 & 0.840 & 1.538 \\
\hline & & & & & $(1.15)$ & $(0.59)$ & $(2.45)$ & $(5.29)$ \\
\hline \multirow[t]{2}{*}{$I_{2} \Delta \pi_{t}$} & & & & & 0.243 & 0.378 & 0.302 & 0.173 \\
\hline & & & & & $(1.20)$ & $(1.85)$ & (1.58) & $(0.86)$ \\
\hline \multirow[t]{2}{*}{$\alpha_{0}$} & -0.241 & 1.210 & -1.279 & 0.952 & 0.148 & 2.247 & -0.217 & 1.078 \\
\hline & $(-0.23)$ & $(0.83)$ & $(-0.57)$ & $(2.08)$ & $(0.14)$ & $(1.24)$ & $(-0.19)$ & $(2.80)$ \\
\hline \multirow[t]{2}{*}{$\beta_{0}$} & 0.237 & -0.042 & -0.084 & 0.233 & 0.344 & 0.123 & 0.044 & 0.181 \\
\hline & $(0.23)$ & $(-0.13)$ & $(-0.25)$ & $(0.64)$ & $(0.73)$ & $(0.17)$ & $(0.09)$ & $(0.45)$ \\
\hline$\alpha_{11}=\beta_{11}=0$ & 0.079 & 0.006 & 0.548 & 0.018 & 0,014 & 0.002 & 0.007 & 0.000 \\
\hline$\alpha_{11}=\beta_{11}=\alpha_{12}=\beta_{12}=0$ & 0.019 & 0.003 & 0.245 & 0.011 & 0,004 & 0.001 & 0.003 & 0.000 \\
\hline
\end{tabular}

Notes: The $t$-statistics are in parentheses.

Consider the estimated single equation ADL threshold cointegration test of the nonlinear Taylor rule for the 1979:4-2005:4 time period with $l_{1 t} \Delta \pi_{t}$ and $l_{2} \Delta \pi_{t}$ : 


$$
\begin{aligned}
& \Delta i_{t}=\left[\underset{(1.24)}{2.247}-\underset{(-3.18)}{0.718} i_{t-1}+\underset{(3.43)}{1.032} \pi_{t-1}+\underset{(2.76)}{0.383} y_{t-1}+\underset{(0.59)}{0.349} \Delta \pi_{t}\right] I_{1 t} \\
& +\left[\underset{(0.17)}{0.123}-\underset{(-1.64)}{0.062} i_{t-1}+\underset{(0.17)}{0.047} \pi_{t-1}+\underset{(6.37)}{0.289} y_{t-1}+\underset{(1.85)}{0.378} \Delta \pi_{t}\right] I_{2 t} .
\end{aligned}
$$

The coefficients of $I_{1 t} i_{t-1}$ and $I_{2 t} t_{t-1}$ are both negative and the $t$-statistics indicate that both are significantly different from zero using a one-sided test. As shown in the right side of Table 8, the test for the joint restriction that both coefficients equal zero has a prob-value of 0.002 and the test for $\alpha_{11}=\beta_{11}=\alpha_{12}=\beta_{12}=0$ also has a prob-value of 0.001 . As such there is strong evidence of a threshold cointegrating relationship with the inflation rate acting as a weakly exogenous variable. Notice that the response is quite similar across the two regimes. Table 8 also reports the IV estimates for the other sample periods (with and without $I_{1} \Delta \pi_{t}$ and $I_{2 t} \Delta \pi_{t}$ ). Although most of the results are similar to those of Eq. (15), it is interesting that, for the 1983:1-2005:4 period, the left-hand-side of Table 8 indicates that we cannot reject the null of no cointegration using either the ADL or ADL2 form of the test. This result seems problematic since cointegration is found to hold over all of the other periods in the sample. However, when we include $I_{1} \Delta \pi_{t}$ and $I_{2} \Delta \pi_{t}$ in the testing equation, the null hypothesis of no cointegration is rejected using either test. Overall, in every sample period we find more rapid adjustment to the equilibrium predicted by the Taylor rule, and a greater policy response to counteract rising inflation, when inflation is above a threshold rate than below this rate.

\subsubsection{Other threshold functions}

We were earlier concerned that the Taylor rule estimates are spurious for the 1983:1-2005:4 period even though the rule seems to work for the surrounding 1979:4-2005:4 and 1987:42005:4 periods. At the risk of over-fitting the data, we experimented with several other possible threshold functions. Overall, no single threshold variable worked as well as the inflation rate. However, a simple modification of Taylor's original specification, such that the threshold is a weighted average of $\pi_{t-d}$ and $y_{t-d}$, yielded interesting results for the 1983:1-2005:4 period. Consider the following threshold function:

$I_{t}=1$ if $w \pi_{t-1}+(1-w) y_{t-1}>\tau$ and $I_{t}=0$ otherwise; $0 \leq w \leq 1$.

The idea is that the regime change depends on a threshold variable that is a combination of the inflation rate and output gap. Taylor's original specification suggested a weight of 0.5 . However, experimentation with values of $w$ equal to $0,0.25$. 0.5 , and 0.75 indicated that the value $w=0.75$ resulted in the best fit (as measured by the log of the determinant of the variance covariance matrix). Consider: 


$$
\begin{aligned}
\Delta i_{t}= & {\left[-\underset{(-3.08)}{0.564} i_{t-1}+\underset{(2.24)}{0.676} \pi_{t-1}+\underset{(2.33)}{0.210} y_{t-1}+\ldots\right] I_{1 t} } \\
& +\left[-\underset{(-1.25)}{0.074} i_{t-1}-\underset{(-0.36)}{0.079} \pi_{t-1}+\underset{(2.05)}{0.149} y_{t-1}+\ldots\right] I_{2 t}
\end{aligned}
$$

where: $t=w \pi_{t-1}+(1-w) y_{t-1}=2.37$.

Notice that the point estimates of the lagged interest rate terms are both negative and the joint hypothesis that they are jointly equal to zero is rejected at the 0.004 significance level.

Moreover, the coefficient on $l_{1 t} \Pi_{t-1}$ is 0.676 and has a $t$-statistic of 2.24 whereas the coefficient on $I_{2 t} \Pi_{t-1}$ is negative, but not statistically different from zero. The joint hypothesis that the two coefficients are jointly equal to zero has a prob-value of 0.077 . It is important to note that the point estimates on the output gap coefficients are both positive and individually significant. As such, we conclude that the Federal Reserve also utilized the output gap as a threshold variable during at least part of the 1983:1-2005:4 period. Notice that the full response of the Fed's reaction to changes in $y_{t-1}$ depends on the slope coefficients for $l_{1 t} y_{t-1}$ and $l_{2 t} y_{t-1}$ and on the intercepts since changes in $y_{t-1}$ can induce the system to cross the threshold value of 2.72. The key point is that the Taylor rule did hold during this latter if the threshold is viewed as time varying.

\section{CONCLUSION}

In this paper, we seek to fill an important gap in the literature by developing new threshold cointegration tests with stationary instrumental variables. An important advantage of our testing procedure is that the test statistics are asymptotically standard (normal or chi-square) and free of the nuisance parameter problems found in other threshold cointegration tests. We use these tests to estimate and test the validity of a nonlinear Taylor rule. While previous studies have estimated nonlinear Taylor rules, no previous studies have tested for nonlinear cointegration, due perhaps to the difficulty of successfully handling the nuisance parameter problem. In contrast to previous tests for threshold cointegration, our testing procedure permits standard inference, even in the presence of stationary covariates. Monte Carlo experiments indicated that our tests have reasonably good size and the power can be substantial when stationary covariates are included. Following the development of our testing methodology, we applied our test to examine several versions of the Taylor rule using U.S. quarterly real-time data from 1970 to 2005. In our nonlinear models, the behavior of the monetary authority is hypothesized to depend on whether inflation is higher or lower than a threshold rate. In contrast to the linear case, our test results find significant evidence of cointegration in the nonlinear models. The estimated coefficients indicate that the Federal Reserve will increase the federal funds interest rate strongly when inflation exceeds a threshold. In contrast, we find substantial policy inertia when inflation is below the threshold. Comparing our sample periods, we find that the Federal Reserve was least aggressive to counteract inflation during the 1970s and most aggressive in the Greenspan era. Finally, we find that a threshold variable combining both inflation and the output gap can better explain monetary policy during the Greenspan era. 


\section{Appendix A}

\section{Proof of Theorem 1}

.See appendix of Enders et al. (2009). The result in Theorem 1 is an extension of the results in Enders et al. (2009). However, note that $\tilde{w}$ w is defined differently here, where $\tilde{w}_{t} \tilde{w} \mathrm{t}=\left(\tilde{w}_{1 t}\right.$

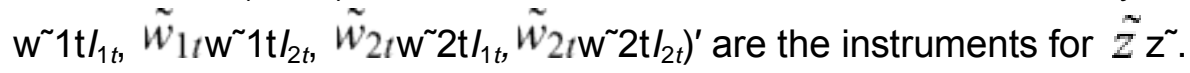

\section{Proof of Theorem 2}

.We assume that the threshold parameter is unknown. First, we examine the case where Condition 1 holds such that $\phi=\gamma$. In such cases, any regime change is confined to the cointegrating terms and a threshold parameter $\tau$ is not identified under the null of no cointegration. In this case, the distribution of the Wald and $t$-statistics will be nonstandard and not chi-square. For the asymptotic distribution of the Wald statistic, we define a continuous residual process $R_{P, Q}(r)$ on $r \in[0,1]$ for a continuous time regression $P(r)=\alpha^{\prime} Q(r)+R_{P, Q}(r)$ as $R P, Q(r)=P(r)-\int Q(r) P(r) d r^{\prime}\left[Q(r) Q\left(r^{\prime}\right) d r^{-1} Q(r), \mathrm{RP}, \mathrm{Q} r=\operatorname{Pr}-\int \mathrm{Q}(\mathrm{r}) \mathrm{P}(\mathrm{r}) \mathrm{dr} \mathrm{r}^{\prime} \mathrm{Q}(\mathrm{r}) \mathrm{Q}(\mathrm{r})^{\prime} \mathrm{dr}-1 \mathrm{Q}(\mathrm{r})\right.$, and the functional

$\Psi\left(R_{1}, R_{2}, \Delta\right)=\operatorname{tr}\left[\left(R_{1}^{\prime} R_{2} \Delta-1 / 2\right)^{\prime}\left(R_{1}^{\prime} R_{1}\right)^{-1}\left(R_{1}^{\prime} R_{2} \Delta-1 / 2\right)\right] . \Psi(\mathrm{R} 1, \mathrm{R} 2, \Delta)=\operatorname{tr}\left[\left(\mathrm{R}^{\prime} 1 \mathrm{R} 2 \Delta-1 / 2\right)^{\prime}\left(\mathrm{R}^{\prime} 1 \mathrm{R} 1\right)-1\left(\mathrm{R}^{\prime} 1 \mathrm{R}\right.\right.$ $2 \Delta-1 / 2)]$.

Then, following Hansen and Seo, 2002 and Seo, 2006, SupWald can have the distribution (A.2)

SupWald $\rightarrow \operatorname{Sup} \Psi\left(R_{1}, R_{2}, \Delta\right)$, where $R_{1}=R_{w, q}(r)$ with $w=\left(w_{m+1}, \ldots, w_{T}\right)^{\prime}$ and $q=\left(q_{m+1}, \ldots, q_{T}\right)^{\prime}, R_{2}=R_{\Delta y, q}(r)$ with $\Delta y=\left(\Delta y_{m+1}\right.$, $\left.\ldots, \Delta y_{T}\right)^{\prime}$, and $\Delta=\hat{\Sigma} \Sigma^{\wedge}$ is obtained from regression (7). The SupWald takes the bounded value of Wald $\left(\hat{\tau}_{T^{\wedge}}\right)$ in Eq. (11) over the range on $\left(c_{1}, c_{2}\right) \in(0,1)$ and $c_{i}=F\left(\hat{\tau}_{T^{\wedge}}\right), i=1,2$, is the empirical percentile of $\hat{\tau}_{T^{\wedge}}$ obtained from the data, regardless of whether the threshold variable is $I(1)$ or $I(0)$. The critical values of the bounded tests in Eq. (A.2) are provided in Table 1.

Second, the more relevant case is the one where Condition $\mathbf{1}$ does not hold $(\phi \neq \gamma)$. In this case, we have a partial stability model where a subset of the parameters will differ in two regimes. The threshold parameter is then identified from the differences in these parameters over different regimes. Finally, it is obvious that the Wald and $t$-statistics using a consistently estimated $\hat{\tau}_{\mathrm{T}^{\wedge}}$ will have the same asymptotic distributions as using a known threshold parameter value as $T \rightarrow \infty$. 


\section{NOTES}

4. Note that Eqs. (2a) and (2b) differ from the usual threshold models, since they include one or more stationary right hand variables, $s_{t}$. In our analysis of the Taylor rule, we find that the output gap is stationary and we want to incorporate this information in our tests. Including stationary covariates in OLS-based cointegration tests is cumbersome, since the test statistics will critically depend on the nuisance parameter $\rho^{2}$ describing the long-run correlation between $u_{t}$ and $v_{t}$, where $v_{t}=\zeta s_{t}+u_{t}$; see Zivot, 2000 and Li, 2006. This outcome is the same in nature as when adding stationary covariates to unit root tests, as initially suggested in Hansen (1995).

5. As noted, $d_{t}$ includes lagged differenced terms to correct for any serial correlation in $u_{1 t}$.

6. It is well known from Hansen (1995) that including stationary covariates makes the usual OLS-based tests dependent on a nuisance parameter.

7. A similar result was suggested by Shin and Lee (2003) for Cauchy IV unit root tests in asymmetric models.

8. Seo (2006) suggests a test for threshold cointegration using the ECM specification. In his test, only $\alpha$ and $\beta$ in Eq. (7) are subject to change in different regimes, while the restriction $\phi=\gamma$ is already imposed. In such cases, $\tau$ cannot be identified under the null of no cointegration. The test in Seo (2006) is based on OLS estimation.

9. A similar approach was suggested by Shin and Lee (2003) in threshold unit root tests.

10. These supreme tests using order statistics depend on the sample size $T$ as well as the endpoints. The critical values of SupWald shown in Table 1 are based on the sample size $T=1000$ obtained using 100,000 replications. Critical values using other sample sizes can be obtained from the authors upon request.

11. The above situation is similar to that found in unit root tests allowing for structural change when the break point is unknown. The difference $|\phi-\gamma|$ virtually corresponds to the coefficient on the dummy variable allowing for structural change in unit root tests. When the break location is known or consistently estimated, the usual exogenous break unit root tests are invariant to this coefficient. However, the situation is different in the OLS endogenous unit root tests as they will critically depend on the break coefficient. In contrast to the exogenous test of Perron (1989), the OLS endogenous unit root tests assume no break under the null and tend to diverge as the magnitude of a break increases (Nunes et al., 1997 and Lee and Strazicich, 2001). Perron (2006) notes that these endogenous break unit root tests are invalid when the break coefficient is a nuisance parameter; see also Byrne and Perman (2007).

12. In the baseline case without a nuisance parameter problem, the OLS-based threshold cointegration tests can be more powerful than the corresponding IV tests. However, while some OLS-based tests lose power when the signal-noise ratio increases, the power of the IV tests increases. Moreover, when stationary covariates are included, the IV based tests gain power without affecting the asymptotic null distribution. In our empirical tests, the null of no cointegration is most often rejected. 
13. Hence, a positive value of $y_{t}$ means that real-time output exceeds the level of 'potential' output.

14. In our tables, we exclude the 1970:1-1979:2 sample period since $i_{t}$ was found to be stationary over this period.

15. For each time period, we begin by using the values of $d$ and $\tau$ shown in Table 7. Given the value of $d=1$ or 2 , we selected $m$ as follows. Holding the threshold value constant, we performed IV estimation using values of $m=4, \ldots, 10$ and selected the value of $m$ resulting in the smallest residual variance. Using this value of $m$, we re-estimated the threshold value $\tau$. We then choose the value of $d$ that results in the smallest residual sum of squares using the optimal values of $m$ and $t$. As such, the values of $d, m$ and $\tau$ are jointly determined.

16. In order to save space, we do not report results treating the output gap as an $/(1)$ process. When we experimented by including $I_{1 t}\left(y_{t-1}-y_{t-m}\right)$ and $I_{2 t}\left(y_{t-1}-y_{t-m}\right)$ as stationary instruments, the results were almost identical to those reported in the paper. In this case, instrumenting a possibly stationary variable had little effect on the results.

17. For brevity, we do not report the stationary dynamics in the tables or in the text.

\section{REFERENCES}

Balke, N.S., Fomby, T.B., 1997. Threshold cointegration. International Economic Review 38, 627-644.

Bec, F., Salem, M.B., Collard, F., 2002. Asymmetries in monetary policy reaction function: evidence for the U.S., French and German central banks. Studies in Nonlinear Dynamics and Econometrics 6 Article 3.

Boivin, J., 2006. Has U.S. monetary policy changed? Evidence from drifting coefficients and real-time data. Journal of Money, Credit, and Banking 38, 1149-1173.

Boswijk, H.P., 1994. Testing for an unstable root in conditional and structural error correction models. Journal of Econometrics 63, 37-60.

Byrne, J.P., Perman, R., 2007. Unit roots and structural breaks: a survey of the literature. In: Bhaskara, Rao B. (Ed.), Cointegration for the Applied Economist, vol. 2. Palgrave Macmillan.

Bunzel, H., Enders, W., 2010. The Taylor Rule and Opportunistic Monetary Policy. Journal of Money, Credit and Banking 42, 931-949.

Chan, K.S., 1993. Consistency and limiting distribution of the least squares estimator of a threshold autoregressive model. The Annals of Statistics 21, 520-533.

Croushore, Dean, Stark, Tom, 2001. A real-time data set for macroeconomists. Working Paper 99-4. : A shortened version of the paper was published in Journal of Econometrics, 105. Federal Reserve Bank of Philadelphia, pp. 111-130. 
Davies, R., 1987. Hypothesis testing when a nuisance parameter is present only under the alternative. Biometrika 74, 33-43.

Enders, W., Falk, B., Siklos, P., 2007. A Threshold Model of Real U.S. GDP and the Problem of Constructing Confidence Intervals in TAR Models. Studies in Nonlinear Dynamics and Econometrics 11, Article 4.

Enders, W., Im, K., Lee, J., 2009. Cointegration Tests Using Instrumental Variables with an Example of the U.K. Demand for Money. Working Paper. University of Alabama.

Enders, W., Siklos, P.L., 2001. Cointegration and threshold adjustment. Journal of Business \& Economic Statistics 19, 166-176.

Hansen, B.E., 1995. Rethinking the univariate approach to unit root tests: how to use covariates to increase power. Econometric Theory 11, 1148-1171.

Hansen, B.E., 1997. Inference in TAR models. Studies in Nonlinear Dynamics and Econometrics 1, 119-131.

Hansen, B., Seo, B., 2002. Testing for two-regime threshold cointegration in vector error correction models. Journal of Econometrics 110, 293-318.

Johansen, S., 1988. Statistical analysis of cointegration vectors. Journal of Economic Dynamics and Control 12, 231-254.

Johansen, S., 1991. Estimation and hypothesis testing of cointegrating vectors in Gaussian vector autoregressive models. Econometrica 59, 1551-1580.

Kremers, J.J.M., Ericsson, N.R., Dolado, J.J., 1992. The power of cointegration tests. Oxford Bulletin of Economics and Statistics 54 (3), 325-348.

Lee, J., Strazicich, M., 2001. Break point estimation and spurious rejections with endogenous unit root tests. Oxford Bulletin of Economics and Statistics 63, 535-558.

Li, J., 2006. Single Equation Tests for Threshold Cointegration with Prespecified Cointegrating Vector. Working Paper. University of Alabama.

Li, J., Lee, J., 2010. ADL Tests for Threshold Cointegration. Working Paper. University of Alabama. Journal of Time Series Analysis 31, 241-254.

Nunes, L., Newbold, P., Kuan, C., 1997. Testing for unit roots with breaks: evidence on the great crash and the unit root hypothesis reconsidered. Oxford Bulletin of Economics and Statistics 59, 435-448.

Orphanides, A., 2001. Monetary policy rules based on real-time data. American Economic Review 91, 964-985.

Österholm, P., 2005. The Taylor rule: a spurious regression? Bulletin of Economic Research 57, 217-247. 
Perron, P., 1989. The great crash, the oil price shock, and the unit root hypothesis. Econometrica 57, 1361-1401.

Perron, P., 2006. Dealing with structural breaks. In: Mills, T.C., Patterson, K. (Eds.), New Palgrave Handbook of Econometrics, vol. 1. MacMillan, London, pp. 278-352.

Qin, T., Enders, W., 2008. In-Sample and Out-of-Sample Properties of Linear and Nonlinear Taylor Rules. Journal of Macroeconomics 30, 428-443.

Seo, M., 2006. Bootstrap testing for the null of no cointegration in a threshold vector error correction model. Journal of Econometrics 134, 129-150.

Shin,D.W., Lee, O., 2003.Aninstrumental variable approach for tests of unit roots and seasonal unit roots in asymmetric time series models. Journal of Econometrics 115, 29-52.

Taylor, John B., 1993. Discretion versus policy rules in practice. Carnegie-Rochester Conference Series on Public Policy 39, 195-214.

Taylor, M.P., Davradakis, E., 2006. Interest rate setting and inflation targeting: evidence of a nonlinear Taylor rule for the United Kingdom. Studies in Nonlinear Dynamics \& Econometrics 10 Article 1.

Zivot, E., 2000. The power of single equation tests for cointegration when the cointegrating vector is prespecified. Econometric Theory 16, 407-439. 